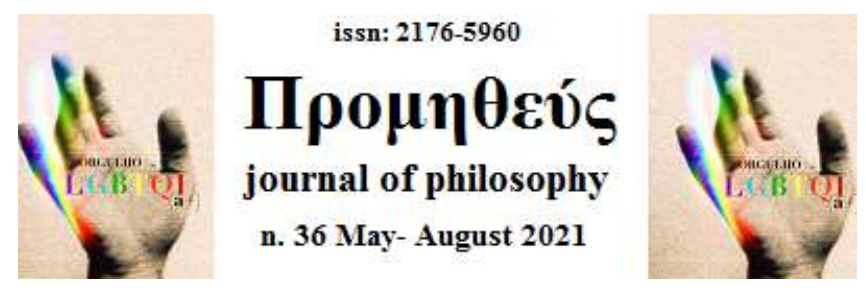

\title{
A PROVIDÊNCIA DIVINA PARA OS FILÓSOFOS ANTIGOS, A CONTRADIÇÃO DE EPICURO E A CAPACIDADE DE DEUS IRAR-SE, TENDO ATRIBUÍDO TAL SENTIMENTO AO FÍGADO DO HOMEM: TRADUÇÃO DOS CAPÍTULOS IX E XXI DA OBRA DE IRA DEI DE LACTÂNCIO
}

\author{
Dr. Cristóvão Santos (Faculdade Olga Mettig) ${ }^{1}$
}

RESUMO: Apresentamos mais um trabalho de tradução da obra De ira Dei de Lactâncio. Desta vez, fornecemos traduções inéditas dos capítulos IX e XXI. Na nona seção, Lactâncio defende a ideia de providência divina, dialogando com a tradição filosófica clássica e questionando alguns pensadores, como Protágoras, Epicuro, Diágoras de Melo e Teodoro de Cirene. Na vigésima primeira seção de sua obra, Lactâncio sustenta que Deus não apenas se ira como também atribuiu tal sentimento ao fígado humano. Saliente-se, ainda, que, novamente, empregamos a edição crítica latina de Christiane Ingremeau (1982).

PALAVRAS-CHAVE: Lactâncio. Ira de Deus. Antiguidade Tardia. Estoicismo. Epicurismo.

ABSTRACT: This paper is another translation of Lactantius' De ira Dei. This time, I do unpublished translations of Chapters IX and XXI. In the ninth section, Lactantius defends the idea of divine providence, dialoguing with the classical philosophical tradition and questioning some thinkers, such as Protagoras, Epicurus, Diagoras of Melos and Theodorus of Cyrene. In the twenty-first section, Lactantius maintains that God not only becomes in wrath but also ascribes this feeling to the human liver. It should also be noted that I used the by Christiane Ingremeau's (1982) Latin critical edition.

KEYWORDS: Lactantius. God's wrath. Late Antiquity. Stoicism. Epicureanism.

\footnotetext{
${ }^{1}$ Professor de Direito da Faculdade Olga Mettig e doutor em Literatura e Cultura pela Universidade Federal da Bahia (UFBA).
} 


\section{Os capítulos IX e XXI da De ira Dei de Lactâncio}

Já tivemos a oportunidade de apresentar Lactâncio em nossas publicações pretéritas $^{2}$. De qualquer modo, considerando que nosso autor é pouco estudado no Brasil e buscando assumir algum grau de didatismo ante o presente leitor, que pode desconhecer nosso projeto de tradução, convém rememorar alguns aspectos elementares atinentes ao autor e à obra em exame.

Ressalte-se, ante isso, que não há, de fato, muitos dados concretos para o conhecimento biográfico de Lúcio Cecílio (ou Célio) Firmiano Lactâncio. Com vistas a seu conhecimento, a fortuna crítica costuma se valer de referências intratextuais, citações e informações contidas nas obras De uiris illustribus e Chronicon, creditadas a Jerônimo de Estridão, que teria vivido entre o final do século IV e início do século V d.C.

Desse modo, costuma-se indicar que Lactâncio teria sido um autor norteafricano originário da Numídia e que teria vivido entre os séculos III e IV d.C. Ele teria sido aluno de Arnóbio de Sica, dedicando-se ao estudo de latim, grego e retórica. Ademais, ele foi preceptor de Crispo, filho de Constantino, que reinou entre 306 e 337 d.C.

A De ira Dei está subdividida em vinte e quatro capítulos, trazendo à balha um conjunto de argumentos balizadores da óptica cristã lactanciana contrária a estoicos e epicuristas. Assim, em cada seção, nosso autor levanta certa hipótese ou combate determinado posicionamento alheio à dogmática defendida. Nesse percurso, Lactâncio parece estabelecer certas correlações com textualidades antigas, no que se sugere a existência de interferências de pensadores como Platão, Cícero e Sêneca, consoante examinado por Christiane Ingremeau (1982) e Luca Gasparri (2013), que forneceram inúmeros subsídios para nosso estudo em notas de tradução ${ }^{3}$.

\footnotetext{
2 Já publicamos as traduções dos Capítulos I, II, III, IV, V, VI, VII, VIII, XIV, XV, XVI e XVII, disponíveis nos sítios eletrônicos presentes na lista final de referências.

3 Também nos valemos de outras traduções para língua estrangeira. Ressalte-se, ante isso, que a De ira Dei já foi traduzida para o italiano por Umberto Boella (1973) e Luca Gasparri (2013); para o alemão
} 
Marca de nosso autor que foi cultivada na nona seção diz respeito à articulação de saberes filosóficos relativos ao paganismo para justificar sua visão teológica. Assim, no Capítulo IX, sustenta-se que, a providência já encontraria fundamento na filosofia antiga $^{4}$, no sentido de que, consoante a própria tradição filosófica, o mundo teria sido construído e regido por uma racionalidade divina.

Dentre suas estratégias de persuasão, Lactâncio recorre inclusive a argumentos de autoridade e ao raciocínio falacioso do argumentum ad hominem em modalidade ofensiva, de forma a desautorizar aqueles pensadores que lhe seriam contrários. Assim, diz-se que Protágoras 5 nihil certi pronuntiauit ("nada de correto exprimiu") e que Diágoras de Melo $^{6}$ e Teodoro de Cirene ${ }^{7}$, muito conhecidos por seu suposto ateísmo, seriam minutos et inertes philosophos ("filósofos ignorantes e insignificantes"). Neste último caso, parece haver um empréstimo da obra De Diuinatione (Sobre a Adivinhação) de Marco Túlio Cícero. Senão vejamos:

62 Epicurum igitur audiemus potius? Namque Carneades concertationis studio modo hoc modo illud ait; ille quod sentit, sentit autem nihil umquam elegans, nihil decorum. Hunc ergo antepones Platoni et Socrati? qui ut rationem non redderent auctoritate tamen hos minutos philosophos vincerent. Iubet igitur Plato sic ad somnum proficisci corporibus adfectis ut nihil sit quod errorem animis perturbationemque adferat. Ex quo etiam Pythagoriis interdictum putatur ne faba vescerentur, quod habet inflationem magnam is cibus tranquillitati mentis quaerenti vera contrariam (grifos nossos) $)^{8}$.

62 Portanto, ouviremos de preferência Epicuro? Pois Carnéades, com seu interesse pela discussão, ora diz isso, ora diz aquilo. Mas aquele fala o que pensa, porém, não pensa nada de criterioso, nada de decoroso. Então tu preferirás este a Platão e Sócrates, que, ainda que não apresentando uma explicação racional, entretanto superariam esses pequenos filósofos pela autoridade? Portanto Platão assim incita a ir dormir com os corpos bem dispostos, de modo que nada ocasione desvio ou perturbação às almas. É por isso, julga-se, que estava proibido aos pitagóricos alimentar-se de fava, pois essa comida causa um grande inchaço do estômago, prejudicial à tranquilidade da mente que busca a verdade (grifos nossos) ${ }^{9}$.

por Gerhard Crone (1952); para o francês por Christiane Ingremeau (1982) e para o inglês por Mary Francis Mcdonald (1965).

4 Embora Lactâncio seja um autor por nós classificado como antigo, ele mesmo já costuma sinalizar certo distanciamento temporal existente entre sua época e aquela dos filósofos clássicos.

5 Protágoras foi um foi um sofista grego pré-socrático do século $\mathrm{V}$ a.C. muito conhecido pela máxima de que "o homem é a medida de todas as coisas".

6 Diágoras de Melos foi um filósofo grego do século V a.C. que teria sido acusado de atentar contra objetos sagrados, ficando conhecido pelo epíteto de ateu.

7 Teodoro de Cirene foi um fílósofo e matemático grego do século V a.C. que teria sido aluno de Protágoras e professor de Platão.

8 Cic. Div. 1.62

9 Tradução de Beatris Ribeiro Gratti (2009). 
Talvez por reconhecer maior grau de "autoridade" em Epicuro, Lactâncio busque enfrentar mais detidamente sua perspectiva, alegando a ocorrência de contradições. Em tal vértice, ele assevera que seria ilógico seguir a ideia epicurista de existência de Deus destituída de providência divina, haja vista que a providência seria da própria natureza da Divindade.

Nesse prisma, quanto à nossa proposta tradutória do Capítulo IX, buscamos empreender, mais uma vez, escrito de caráter técnico que cultivasse certa sistematização lexical, valorizando ainda, em alguma medida, o arcabouço semântico-gramatical do texto de partida, associado aos casos e à sintaxe latina. Espera-se, nesse sentido, fornecer texto que tenha linguagem acessível, mas que também seja funcional para os estudiosos da área. Note-se, ainda, que foram empregadas, novamente, unidades lexicais que sugerem para o leitor hodierno aproximação do universo de embate entre perspectivas filosóficas e teológicas. Assim, há termos que remetem ao meio religioso, como "Providência" para prouidentia, "teria sido edificado" para esset instructus, "Divindade" para diuinitas, "ímpia" para inpia, "verdade" para ueritatem, "religião" para religionem, "abençoado" para beatum, "foi professado" para professus est e "ateu" para atheus. Por outro lado, também foram cultivados elementos que se relacionam à seara filosófica, como "razão" para ratione, "natureza das coisas" para naturam rerum e "devêssemos refutar" para refellemus ("refutaremos"), além das referências diretas a determinados pensadores como "Protágoras" para Protagoras, "Sócrates" para Socrates, "Platão" para Plato, "estoicos" para Stoici, "peripatéricos" para Peripatetici, "Epicuro" para Epicurus, "Diágoras de Melo" para Melius Diagora e "Teodoro de Cirene" para Cyrenaeus Theodorus. Ainda em valorização ao estilo lactanciano, realizamos amplo emprego de operadores argumentativos e de termos de realce ou intensivos, como em "certamente" para quidem, "absolutamente" para utique, "mesmo" para prorsus e "verdadeiramente" para uero.

No que concerne ao Capítulo XXI, Lactâncio refuta a ideia de que Deus não poderia irar-se já que, em seus próprios mandamentos, proibiria tal sentimento ao homem. Visando a justificar a cólera divina, assevera que Deus não proibiria a ira por completo, mas sim a permanência humana nesse sentimento. A própria ira do homem ensejaria punições que seriam valiosas ao conhecimento da justiça e da retidão moral. Assim, segundo Lactâncio, a ira, quando efêmera, seria aceitável, em decorrência da exemplaridade gerada pela justa retificação de condutas inadequadas. Em realidade, o 
próprio Deus teria reservado esse sentimento ao fígado humano, conforme a seção quatro do capítulo traduzido, indicada a seguir:

4. Sed tamen non ita se res habet. Nam si omnino prohiberet irasci, ipse quodammodo reprehensor opificii sui fuisset, qui a principio iram iecori hominis indidisset, siquidem creditur causa huius commotionis in umore fellis contineri (grifos nossos)

4. No entanto, o problema não se soluciona assim. Na realidade, se se proibisse completamente de irar-se, Ele próprio, de certo modo, teria sido repreensor de sua obra, pela qual, em princípio, teria atribuído a ira ao fígado do homem, uma vez que se acredita que essa emoção está contida no humor do fel (grifos nossos).

Essa referência ao fígado pode, conforme sinalizado em nota na tradução italiana de Gasparri (2013), indicar algum reflexo de Platão (séc V - séc. IV a.C.). Assim, merecem destaque os seguintes trechos, que foram extraídos do diálogo Timeu:

\footnotetext{
Quanto à parte da alma que deseja comida e bebida e tudo aquilo de que o corpo tem necessidade por natureza, essa parte eles estabeleceram entre o diafragma e o limite do umbigo, fabricando em toda esta região uma espécie de manjedoura para o sustento do corpo ${ }^{10}$. [...] De acordo com isto, um deus delineou um plano conforme à sua intenção: constituiu a espécie do fígado e estabeleceu-o na morada desta parte da alma. Fabricou-o espesso, liso e brilhante e contendo doce e amargor, para que a potência das noções, ao transportá-las do intelecto até ele, como num espelho que recebe impressões e fornece reflexos a quem o contemplar, o atemorizasse, ao trazer-lhe ameaças terríveis e, fazendo uso da sua parte congénere que tem amargor, espalhasse o amargo por todo ele e fizesse aparecer as cores da bílis, contraindo-o até se fazer áspero e todo rugoso, vergando e contraindo o lobo a partir da posição correta e obstruindo e fechando a vesícula e as entradas, de modo a provocar dores e náuseas. Em sentido oposto, quando algum movimento inspiratório reflete do pensamento simulacros de suavidade, converte o amargor em tranquilidade, pois esse movimento não quer ser anexado a uma natureza contrária à sua ${ }^{11}$.
}

Embora Lactâncio tenha enfatizado apenas a ira como sentimento atribuído ao fígado, conforme Platão, um deus teria delineado tal órgão como sede de sentimentos negativos, como a ira, mas também positivos, como a tranquilidade. Desse modo, na óptica platônica, o fígado se relacionaria à parte da alma mais instintiva e alheia à razão.

Por fim, quanto ao texto de chegada proposto do Capítulo XXI, intentamos, similarmente, atentar para as marcas retóricas e religiosas da produção lactanciana, cultivando seu amplo emprego de operadores argumentativos e de lexias vinculadas ao universo cristão. Assim, o vocábulo nam, com quatro ocorrências, foi traduzido quatro vezes por "na realidade"; enim, com três ocorrências, foi traduzido três vezes por "de fato"; quia, com sete ocorrências, foi traduzido sete vezes por "visto que"; sed, com sete

\footnotetext{
${ }^{10}$ Plat. Tim. 70d-e. As traduções do diálogo Timeu são de Rodolfo Lopes (2011).

${ }^{11}$ Plat. Tim. 71a-c.
} 
ocorrências, foi traduzido sete vezes por "mas"; sed tamen, com duas ocorrências, foi traduzido duas vezes por "no entanto"; autem, com uma ocorrência, foi traduzido uma vez por "contudo"; itaque, com duas ocorrências, foi traduzido duas vezes por "e assim"; ita, com uma ocorrência, foi traduzido uma vez por "assim"; fortasse, com uma ocorrência, foi traduzido uma vez por "talvez"; ergo, com uma ocorrência, foi traduzido uma vez por "logo"; igitur, com uma ocorrência, foi traduzido uma vez por "portanto"; quoque, com uma ocorrência, foi traduzido uma vez por "também"; ut etiam, com uma ocorrência, foi traduzido uma vez por "como também"; quodammodo, com uma ocorrência, foi traduzido uma vez por "de certo modo"; numquam, com uma ocorrência, foi traduzido uma vez por "nunca"; saepe, com uma ocorrência, foi traduzido uma vez por "muitas vezes"; deus, com seis ocorrências, foi traduzido seis vezes por "Deus"; in aeternum, com três ocorrências, foi traduzido três vezes por "eternamente"; aeternus, com duas ocorrências, foi traduzido duas vezes por "eterno"; temporalis, com duas ocorrências, foi traduzido duas vezes por "passageiro"; omnino, com uma ocorrência, foi traduzido uma vez por "completamente"; furor, com uma ocorrência, foi traduzido uma vez por "furor"; dicere, com três ocorrências, foi traduzido três vezes por "dizer"; rex, com uma ocorrência, foi traduzido uma vez por "rei"; quaestio, com uma ocorrência, foi traduzido uma vez por "questão"; iniuste, com uma ocorrência, foi traduzido uma vez por "injustamente"; inexpiabilis, com uma ocorrência, foi traduzido uma vez por "inexpiável”; manere, com três ocorrências, foi traduzido três vezes por "prosseguir"; permanere, com uma ocorrência, foi traduzido uma vez por "permanecer"; mortalis (adj.), com duas ocorrências, foi traduzido duas vezes por "mortal"; mortale (sub.), com uma ocorrência, foi traduzido uma vez por "mortal"; inmortalis, com uma ocorrência, foi traduzido uma vez por "imortal"; praesens, com uma ocorrência, foi traduzido uma vez por "instantâneo"; praesentaneaus, com uma ocorrência, foi traduzido uma vez por "imediato"; castigatio, com uma ocorrência, foi traduzido uma vez por "castigo"; facinus, com uma ocorrência, foi traduzido uma vez por "transgressão"; delictum, com uma ocorrência, foi traduzido uma vez por delito; punire, com uma ocorrência, foi traduzido uma vez por "punir"; uirtus, com duas ocorrências, foi traduzido duas vezes por "virtude"; placabilis, com uma ocorrência, foi traduzido uma vez por "calmo"; placor, com duas ocorrências, foi traduzido duas vezes por "acalmar-se".

\section{Texto de partida latino do Capítulo IX}


9, 1. Cum sententiae philosophorum prioris temporis de prouidentia consensissent nec ulla esset dubitatio quin mundus a deo et ratione esset instructus et ratione regeretur, primus omnium Protagoras extitit temporibus Socratis, qui sibi diceret non liquere utrum esset aliqua diuinitas necne.2. Quae disputatio eius adeo inpia et contra ueritatem et religionem iudicata est, ut et ipsum Athenienses expulerint suis finibus et libros eius in contione quibus haec continebantur exusserint. De cuius sententia non est opus disputare, quia nihil certi pronuntiauit. 3. Post haec Socrates ipse et auditor eius Plato et qui de schola Platonis tamquam riuuli diuersas in partes profluxerunt, Stoici et Peripatetici, in eadem fuere sententia qua priores.

4. Postea uero Epicurus deum quidem esse dixit, quia necesse sit esse aliquid in mundo praestans et eximium et beatum, prouidentiam tamen nullam: itaque mundum ipsum nec ratione ulla nec arte nec fabrica instructum, sed naturam rerum quibusdam minutis seminibus et insecabilibus conglobatam. 5. Quo quid repugnantius dici possit non uideo. Etenim, si est deus, utique prouidens est, ut deus, nec aliter ei potest diuinitas tribui, nisi et praeterita teneat et praesentia sciat et futura prospiciat. 6. Cum igitur prouidentiam sustulit, etiam deum negauit esse. Cum autem deum esse professus est, et prouidentiam simul esse concessit: alterum enim sine altero nec esse prorsus nec intellegi potest.

7. Verum his postea temporibus quibus iam filosofia defloruerat, extitit Melius quidam Diagoras, qui nullum esse omnino deum diceret ob eamque sententiam nominatus est atheus, item Cyrenaeus Theodorus; et ambo, quia nihil noui poterant reperire omnibus iam dictis et inuentis, maluerunt contra ueritatem id negare in quo priores uniuersi sine ambiguitate consenserant. Hi sunt qui tot saeculis tot ingeniis adsertam atque defensam prouidentiam calumniati sunt. 8. Quid ergo? Vtrumne istos minutos et inertes philosophos ratione, an uero auctoritate praestantium uirorum refellemus, an potius utroque? Sed properandum est, ne longius a materia diuagetur oratio.

\section{Texto de chegada em língua portuguesa do Capítulo IX}

9, 1. Visto que as opiniões dos filósofos da era antiga teriam consentido sobre a Providência, não haveria nenhuma dúvida de que, realmente, o mundo tanto com a razão teria sido edificado como com a razão seria regido por Deus. Em primeiro lugar, Protágoras, que viveu nos tempos de Sócrates, teria dito que a Divindade ou sua inexistência não lhe seriam de qualquer forma evidentes. 2. Essa sua declaração foi 
considerada tão ímpia e contrária à verdade e à religião que os Atenienses tanto o teriam banido de suas fronteiras como teriam queimado, em praça pública, seus livros, que continham afirmações desse gênero. Não é necessário dissertar sobre sua opinião, que não exprimiu nada de correto. 3. Depois disso, tanto o próprio Sócrates como seu discípulo Platão e os estoicos e peripatéticos - que da escola de Platão, como que em canais, fluíram por partes diversas - tiveram, do mesmo modo, a opinião que os anteriores.

4. Posteriormente, no entanto, Epicuro disse certamente existir um Deus, já que seria necessário que existisse, no mundo, algo superior, excelente e abençoado, todavia sem Providência: e assim o próprio mundo não teria sido edificado por alguma razão, arte ou ofício, mas a natureza das coisas teria sido conglobada por alguns elementos pequenos e indivisíveis. 5. Não vejo como algo mais contraditório do que isso pode ser dito. Na realidade, se Deus existe, Ele é absolutamente providente como Deus, e a divindade não the poderia ser diversamente atribuída, se Ele não conservasse as coisas passadas, conhecesse as presentes e previsse as futuras. 6. Portanto, quando suprimiu a Providência, Epicuro também negou que Deus existisse. Quando foi professado que Deus existe, Epicuro deveria, contudo, ter reconhecido simultaneamente a Providência: de fato, um não pode mesmo existir nem ser concebido sem o outro.

7. Posteriormente, contudo, naqueles tempos em que a filosofia já havia perdido seu vigor, existiu um certo Diágoras de Melo, que teria dito que não existiria, de nenhum modo, Deus e, por causa dessa opinião, foi chamado de ateu, à semelhança de Teodoro de Cirene. Ambos - já que nada de novo podiam descobrir além de tudo aquilo que já tinha sido dito e cogitado - preferiram ir contra a verdade e negar o que todos anteriores tinham consentido sem qualquer ambiguidade. Estes são os que caluniaram a Providência, afirmada e defendida por tantos séculos e por tantos gênios. 8. E daí? Talvez devêssemos refutar, com a razão, esses filósofos ignorantes e insignificantes ou talvez deveríamos debater com a autoridade de homens verdadeiramente superiores, ou talvez melhor, com ambos? Mas devemos nos apressar, para que o discurso não se afaste muito da matéria.

\section{Texto de partida latino do Capítulo XXI}

21, 1. Superest una et extrema quaestio. Nam dixerit fortasse quispiam adeo non irasci deum ut etiam in praeceptis hominem irasci uetet. 
2. Possem dicere quod ira hominis refrenanda fuerit, quia iniuste saepe irascitur et praesentem habet motum, quia temporalis est. 3. Itaque, ne fierent ea quae faciunt per iram et humiles et mediocres et magni reges, temperari debuit furor eius et conprimi, ne mentis inpos aliquod inexpiabile facinus admitteret. Deus autem et non ad praesens irascitur quia aeternus est perfectaeque uirtutis, et numquam nisi merito irascitur.

4. Sed tamen non ita se res habet. Nam si omnino prohiberet irasci, ipse quodammodo reprehensor opificii sui fuisset, qui a principio iram iecori hominis indidisset, siquidem creditur causa huius commotionis in umore fellis contineri. 5. Non igitur in totum prohibet irasci, quia is adfectus necessario datus est, sed prohibet in ira permanere; ira enim mortalium debet esse mortalis. Nam si maneat, confirmantur inimicitiae ad perniciem sempiternam. 6. Deinde rursum, cum irasci quidem sed tamen non peccare praecepit, non utique euellit iram radicitus sed temperauit, ut in omni castigatione modum ac iustitiam teneremus.

7. Qui ergo nos irasci iubet, ipse utique irascitur, qui placari celerius praecipit, est utique ipse placabilis; ea enim praecipit quae sunt iusta et rebus utilia communibus.

8. Sed quia dixeram non esse iram dei temporalem sicut hominis, qui praesentanea commotione feruescit nec facile regere se potest propter fragilitatem, intellegere debemus, quia sit aeternus deus, iram quoque eius in aeternum manere, sed rursum, quia uirtute sit maxima praeditus, in potestate habere iram suam nec ab ea regi, sed ipsum illam quemadmodum uelit moderari; quod utique non repugnat superiori. 9. Nam si prorsus inmortalis fuisset ira eius, non esset satisfactioni aut gratiae post delictum locus, cum ipse homines reconciliari iubeat ante solis occasum; sed ira diuina in aeternum manet aduersus eos qui peccant in aeternum.

10. Itaque deus non ture, non hostia, non pretiosis muneribus quae omnia sunt corruptibilia, sed morum emendatione placatur, et qui peccare desinit iram dei mortalem facit. Idcirco enim non ad praesens noxiumquemque punit, ut habeat homo resipiscendi et corrigendi sui facultatem.

\section{Texto de chegada em língua portuguesa do Capítulo XXI}

21, 1. Resta apenas uma única e última questão. Na realidade, talvez alguém tenha dito que Deus não se ira, como também, em seus mandamentos, proibiria o homem de irar-se.

2. Eu poderia dizer que a ira do homem deveria ter sido reprimida, visto que ele se ira muitas vezes injustamente e tem um impulso instantâneo, visto que é um ser 
passageiro. 3. E assim, para que não ocorressem as coisas que os humildes, os medíocres e os grandes reis fazem por ira, Ele teve que conter e comprimir o furor do homem, para que ele, sem o controle de sua mente, não perpetrasse nenhuma transgressão inexpiável. Deus, contudo, não se ira instantaneamente, visto que é eterno e de virtude perfeita, e nunca se ira a não ser merecidamente.

4. No entanto, o problema não se soluciona assim. Na realidade, se se proibisse completamente de irar-se, Ele próprio, de certo modo, teria sido repreensor de sua obra, pela qual, em princípio, teria atribuído a ira ao fígado do homem, uma vez que se acredita que essa emoção está contida no humor do fel. 5. Portanto, Ele não proíbe inteiramente que se ire, visto que esse sentimento foi necessariamente dado, mas Ele pró́be que se permaneça na ira. De fato, a ira dos mortais deve ser mortal. Na realidade, se ela prossegue, as inimizades se consolidam até a perpétua destruição. 6. E então, por outro lado, quando prescreveu irar-se, no entanto sem pecar, Ele não eliminou, por absoluto, a ira desde suas raízes, mas a regulou, para que, com cada castigo, recordássemos o limite e a justiça.

7. Logo, aquele que ordena que nos iremos, certamente, Ele próprio se ira; aquele que prescreve que nos acalmemos mais rápido, certamente, Ele próprio é calmo; de fato, Ele prescreve essas coisas, que são justas e úteis aos interesses comuns.

8. Mas, visto que eu tinha dito que a ira de Deus não é passageira como a do homem, que se enfurece com uma emoção imediata, e não pode reger-se facilmente em razão de sua fraqueza, devemos entender, visto que Deus seria eterno, que sua ira também prossegue eternamente, mas, por outro lado, visto que seria elevado por sua máxima virtude, Ele tem sua ira sob seu poder e não se rege por ela, mas Ele próprio a controla do mesmo modo que deseja, o que, absolutamente, não se opõe ao supramencionado. 9. Na realidade, se sua ira fosse propriamente imortal, não existiria lugar para satisfação ou bondade após um delito, quando Ele próprio ordenaria aos homens que se reconciliem antes do pôr do sol. Mas a ira divina prossegue eternamente contra os que pecam eternamente.

10. E assim, Deus se acalma não por incenso, nem por sacrifício, nem por presentes preciosos, os quais são todos transitórios, mas pela correção dos costumes, e quem cessa de pecar torna a ira de Deus mortal. Por esse motivo, de fato, Ele não pune instantaneamente cada um que causa dano, para que o homem tenha a faculdade de se regenerar e se corrigir. 


\section{REFERÊNCIAS}

BOELlA, U. (1973). Institutiones, De opificio Dei, De ira Dei. Classici della Filosofia cristiana 5. Firenze: Sansoni.

CRONE, G. (1952). Lactantius; eine Auswahl aus der Epitome, De ira Dei, und De mortibus persecutorum. Paderborn: Schöningh.

GASPARRI, L (2013). Lattanzio: la collera di Dio. Bompiani: Milão.

GRATTI, B. Sobre a advinhação, de Marco Túlio Cícero. 2009. 239 f. Dissertação (Mestrado em Linguística) - Instituto de Estudos da Linguagem, Universidade Estadual de Campinas, Campinas, 2009.

LACTANCE, (1982). La Colère de Dieu, introduction, texte critique, traduction, commentaire et index par C. Ingremeau, Paris Éd. du Cerf.

MCDONALD, M. (1965). Lactantius: The Minor Works. The Fathers of the Church 54. Washington: Catholic University of American Press.

PLATÃO. (2011) Timeu-Crítias. Trad. Rodolfo Lopes. Coimbra: Centro de Estudos Clássicos e Humanísticos.

SANTOS JÚNIOR, C (2020a). Sócrates e a inexistência de sabedoria humana, por Lúcio Cecílio Firmiano Lactâncio: tradução do capítulo I da obra De ira Dei. Hypnos, São Paulo, v. 45, p. 274-280. Disponível em:

https://hypnos.org.br/index.php/hypnos/article/view/626. Acesso em: 11 out. 2020.

SANTOS JÚNIOR, C (2020b). A destruição dos fundamentos da religião por Epicuro: tradução do capítulo VIII da obra De ira Dei de Lúcio Cecílio Firmiano Lactâncio. Revista Escripturas, v. 04, p. 291-301. Disponível em: https://www.revistaescripturas.com/20202-6. Acesso em 19/03/2021.

SANTOS JÚNIOR, C (2020c). Cícero e o propósito da criação do homem: tradução do capítulo XIV da obra De ira Dei de Lúcio Cecílio Firmiano Lactâncio. Rónai, v. 8, p. 108-115. DOI: https://doi.org/10.34019/2318-3446.2020.v8.31726. Disponível em: https://periodicos.ufjf.br/index.php/ronai/article/view/31726. Acesso em: 18/03/2021.

SANTOS JÚNIOR, C (2020d). Os três degraus para o alcance da verdade, por Lúcio Cecílio Firmiano Lactâncio: tradução do capítulo II da obra De ira Dei. Caletroscópio, v. 8, p. 46-54. Disponível em:

https://periodicos.ufop.br:8082/pp/index.php/caletroscopio/article/view/4460. Acesso em $24 / 03 / 2021$.

SANTOS JÚNIOR, C (2021a). As quatro hipóteses do adfectus divino e As diferenças entre o homem e os animais: tradução dos capítulos III, IV, V, VI e VII da obra De ira Dei de Lúcio Cecílio Firmiano Lactâncio. TRANSLATIO, v. 1, p. 170-186. Disponível em: https://www.seer.ufrgs.br/translatio/article/view/112919. Acesso em 20/06/2021. 
SANTOS JÚNIOR, C (2021b). A diferença entre os sentimentos humanos e divinos, a coexistência de ira, amor e misericórdia em Deus e a diferença entre a ira justa e a injusta: tradução dos capítulos XV, XVI e XVII da obra De ira Dei de Lactâncio.

NEARCO (RIO DE JANEIRO), v. 13, p. 393-411. Disponível em: https://www.epublicacoes.uerj.br/index.php/nearco/article/view/58813. Acesso em 21/06/2021. 